\title{
El reencuentro con el lugar: nuevas ruralidades, nuevos paisajes y cambio de paradigma
}

\author{
Joan Nogué
}

Universitat de Girona. Departament de Geografia

Observatori del Paisatge de Catalunya

joan.nogue@udg.edu

\section{Resumen}

Estamos asistiendo a un reencuentro con el lugar a través de nuevas e imaginativas fórmulas, como resultado de un cambio de paradigma liderado por una sociedad civil que entiende la acción política de otra manera. Una sociedad civil que no tiene ningún problema en reconocer la importancia que tiene vincular las emociones a los lugares, a los paisajes y, en general, a la gestión del espacio público. Emergen en el mundo rural nuevos proyectos y actitudes, nuevos valores, nuevas formas de organización social que, en algunos casos, surgen casi de la nada y, en otros, se han reforzado precisamente gracias a la hecatombe económica, social y cultural provocada por la tan manida crisis económica.

Palabras clave: lugar; ruralidad; paisaje; cambio de paradigma

Resum. El retrobament amb el lloc: noves ruralitats, nous paisatges $i$ canvi de paradigma

Estem assistint a un retrobament amb el lloc a través de noves i imaginatives fórmules, com a resultat d'un canvi de paradigma liderat per una societat civil que entén l'acció política d'una altra manera. Una societat civil que no té cap problema a reconèixer la importància que té vincular les emocions amb els llocs, amb els paisatges i, en general, amb la gestió de l'espai públic. Emergeixen en el món rural nous projectes i actituds, nous valors, noves formes d'organització social que en alguns casos sorgeixen del no-res i en d'altres s'han reforçat precisament gràcies a la catàstrofe econòmica, social i cultural provocada per la crisi econòmica.

Paraules clau: lloc; ruralitat; paisatge; canvi de paradigma 
Résumé. La redécouverte du lieu: nouvelles ruralités, nouveaux paysages et changement de paradigme

Nous assistons à une redécouverte du lieu à travers des formules nouvelles et imaginatives, fruits d'un changement de paradigme porté par une société civile qui appréhende l'action politique d'une autre façon. Cette société civile reconnaît naturellement l'importance de lier les émotions aux lieux, aux paysages et à la gestion de l'espace public en général. Le monde rural voit émerger de nouveaux projets, des attitudes et des valeurs nouvelles, ainsi que des formes alternatives d'organisation sociale surgissant dans certains cas ex nibilo et qui dans d'autres, se sont précisément consolidées grâce à l'hécatombe économique, sociale et culturelle provoquée par la crise économique dont on a tant parlé.

Mots-clés: lieu; ruralité; paysage; changement de paradigme

\begin{abstract}
Rediscovering Place: New Ruralities, New Landscapes and a Paradigm Shift
We are witnessing a rediscovery of place through new and imaginative formulae, as a result of the shift in paradigm led by civil society which understands political action differently. A civil society that has no difficulty acknowledging the importance of tying emotions to places, landscapes and, generally speaking, management of the public space. The rural world is seeing the emergence of new initiatives and attitudes, new values, new forms of social organisation that in some cases arise almost from nowhere and, in other cases, have been reinforced precisely on account of the economic, social and cultural catastrophe brought about by the tired references to the economic crisis.
\end{abstract}

Keywords: place; rurality; landscape; paradigm shift

\title{
Sumario
}

Hacia un cambio de paradigma Conclusiones

Nuevas ruralidades, nuevos paisajes Referencias bibliográficas

Las relaciones que la gente mantiene con los lugares están cambiando de manera notoria y ello se percibe aún con más claridad en esta crisis sistémica en la que estamos inmersos; crisis que, cuanto más pasa el tiempo, más se demuestra que, efectivamente, no es solo una crisis económica, sino también una crisis de valores, de modelo de sociedad, de formas de vida. La geografía tiene mucho que decir al respecto, porque la plasmación territorial de dicha crisis y el cambio en la manera de relacionarnos con los lugares que está generando son dos de sus dimensiones fundamentales. En este contexto estamos asistiendo a un reencuentro, a un redescubrimiento del lugar y en este proceso el mundo rural está adquiriendo un renovado papel. Desarrollaré esta idea en tres bloques. En el primero esbozaré un diagnóstico general de la situación; en el segundo bloque, el central, mostraré ocho ejemplos muy dispares entre sí, pero suficientemente ilustradores del cambio que, en la línea antes apuntada, intuyo en el entorno rural. Finalmente, apuntaré unas breves conclusiones. 


\section{Hacia un cambio de paradigma}

¿Qué es exactamente lo que está pasando? ¿Por qué tenemos la sensación de "fin de etapa», de "fin de ciclo»? ¿Por qué parece que una determinada forma de entender nuestro entorno, de gestionarlo y de relacionarnos con él está llegando a su fin? ¿Por qué sentimos una renovada necesidad de reinventar y reinterpretar los lugares? Es una evidencia que este tipo de cuestiones se plantean hoy en día y de manera reiterada en foros nacionales e internacionales de todo tipo y condición. Es el caso del seminario internacional «Curare la terra. Luoghi, pratiche, esperienze», organizado por la Fondazione Benetton Studi Ricerche y celebrado los días 20 y 21 de febrero de 2014 en Treviso (Italia). La expresión curare la terra ("cuidar la tierra»), tema central del seminario, se refería al conjunto de nuevas prácticas, experiencias y actitudes que indican una renovada actitud mental ante los lugares por parte de la sociedad contemporánea, y no solo en los espacios rurales, sino también en general, si bien es verdad que en los espacios rurales es donde esa actitud se hace más evidente. Los organizadores se vieron desbordados por el éxito de la convocatoria: casi trescientas personas de todos los rincones del país - y del extranjero-, procedentes de sectores profesionales muy diversos se inscribieron al mismo. Poco después, en Burdeos (Francia), se celebraba otro seminario internacional con un título aún más breve, pero estrechamente relacionado con el anterior: «L'appartenir» (Pertenecer, el hecho de pertenecer... un verbo de difícil traducción). Y así podríamos seguir en las páginas siguientes, mostrando ejemplos de todo tipo que mostrarían el interés que está despertando esta especie de «redescubrimiento» (más que de «retorno») al lugar. ¿Qué está pasando?

Desde mi punto de vista, la razón fundamental es que estamos asistiendo a un cambio de paradigma en el sentido más amplio de la palabra. Las clásicas estructuras materiales e ideológicas que creíamos infalibles se están resquebrajando, están perdiendo su aura de solidez y de consistencia. Los pilares del sistema de producción y de consumo hegemónico muestran grietas y el modelo de crecimiento y los valores sociales imperantes se ven cuestionados por nuevas actitudes ante el trabajo, ante los recursos naturales, ante el lugar. Se reclama una vida más plena, más llena de sentido, en la que el individuo sea dueño de su destino, controle su propio tiempo, se alimente de manera más sana y viva una existencia en plenitud. Por otra parte, la progresiva concienciación ambiental de las últimas décadas ha comportado no solo una reacción mundial ante el cambio climático producido por el calentamiento global, sino también una actitud mucho más respetuosa hacia los ecosistemas naturales y la biodiversidad del planeta. Concepto —el de biodiversidad— cada vez más asociado al de biodiversidad cultural.

Y a todo ello hay que añadir el hecho de que la sociedad civil ha aprendido a organizarse para responder a una Administración a menudo rígida y anquilosada y a un sector de la clase política muy alejado de lo que realmente preocupa a la ciudadanía. Esta situación se ha visto agudizada, coyunturalmente, por la actual crisis económica, que ha puesto de manifiesto el descontrol de un 
sistema financiero que hasta entonces había presumido de solidez y consistencia. Mucha gente ha perdido la fe en el sistema y, en consecuencia, los pilares fundamentales de dicho sistema han perdido la categoría de dogma.

Así pues, algo pasa, algo se mueve en el ámbito cultural, social, territorial, económico, también en el ético, e incluso en el estético (Carlson, 2009). Sí, también en el ámbito estético, porque ética y estética caminan juntas, siempre. Este «algo», este cambio de paradigma señalado es lo que en buena medida explica que miremos a los lugares de otra manera, mucho más emocionalmente (Nogué, 2010). La modernidad nos indujo a pensar que el espacio geográfico era un espacio geométrico, casi topológico, y que los lugares eran simples localizaciones fácilmente identificables en nuestros mapas a partir de un sistema de coordenadas que nos señalaba su latitud y su longitud. Y ahora nos damos cuenta de que eso no es exactamente así, sino que el espacio geográfico es, fundamentalmente, un espacio existencial, conformado por lugares cuya materialidad tangible está teñida, bañada de elementos inmateriales e intangibles que convierten a cada lugar en algo único e intransferible. Lo sabíamos. El mundo ha sido siempre así y los lugares siempre se vivieron de esa manera, pero en las últimas décadas lo olvidamos. Ahora, por fin, lo estamos recuperando y no solo por efecto de la tan manida crisis. Los profesionales de la ordenación del territorio y de la planificación urbana y regional lo están redescubriendo porque se dan cuenta de que muchos de los instrumentos de ordenación y de planificación clásicos, convencionales, ya no funcionan o - quizá es más correcto decirlo de otra manera- muestran serias dificultades para dar respuesta a las nuevas necesidades sociales y a los nuevos cambios culturales. Incluso algunas de las políticas de paisaje existentes en Europa, que hasta hace poco nos parecían tan innovadoras, no se están mostrando tan eficaces como esperábamos, quizás porque, en muchos casos, no atacaban la raíz del problema, sino que, en el fondo, eran de carácter más bien cosmético y se limitaban a corregir, a camuflar, a embellecer los excesos, los abusos de intervenciones desafortunadas que nunca entendieron el lugar en el que se implantaban y que, de hecho, nunca debieron haberse implantado allí.

Así pues, se mire por donde se mire y admitiendo que la situación descrita varía en cuanto a forma e intensidad de un país a otro, lo cierto es que estamos en transición hacia un nuevo escenario, también en el mundo rural (Bruno, 2014; Clementi, 2012; Pascale, 2014; Rauch, 2014; Rubino, 2010).

\section{Nuevas ruralidades, nuevos paisajes}

Voy a exponer a continuación ocho ejemplos muy dispares entre sí, pero suficientemente ilustradores del cambio que, en la línea antes apuntada, intuyo en el entorno rural, y son los siguientes (incidiré sobre todo en el primero de ellos):

- La emergencia de un nuevo neorruralismo.

- La proliferación de circuitos alternativos de producción y de consumo. 
— La reinvención de antiguas profesiones como estrategia de recuperación del carácter del lugar.

- La recuperación de la esencia del lugar como estrategia de revitalización económica y cambio cultural.

- La revitalización de áreas marginales y despobladas a través de proyectos culturales de calidad.

- La emergencia de nuevas formas de gestión del territorio de carácter horizontal y comunitario.

- El ensayo de nuevas formas de gobernanza local.

- El renovado papel de los centros de estudios locales y comarcales.

Soy consciente de que, a escala mundial, las grandes problemáticas con las que se enfrentan los espacios agrarios contemporáneos son otras, que aquí no trato, pero que sí quiero recordar, al menos algunas de ellas (Aubert, Piveteau, Schmitt, 2009; Palang, 2004; Perrier-Cornet, 2002; Renard, 2002; Wolfer, 2010): la competencia por el recurso agua, la compra y acaparamiento de tierras por parte de algunas potencias emergentes y de fondos de inversión internacionales, el dilema de los biocombustibles, el control de granos y semillas por parte de un puñado de multinacionales, el futuro de la agroindustria regional, los espacios agrarios periurbanos, el reto de las masas forestales abandonadas en un rincón del planeta y el reto de la deforestación en el otro, el cambio climático y su impacto en la agricultura, la pérdida de suelo agrícola de calidad, el agroturismo, la agricultura social y otros tantos temas capitales. De todas estas problemáticas, las que considero especialmente preocupantes son la compra y acaparamiento de tierras por parte de algunas potencias emergentes y de fondos de inversión internacionales y el control de granos y semillas en unas pocas manos. Ante nuestros ojos se está escribiendo «la historia invisible de la desaparición de la biodiversidad» (Conill et al., 2012: 39). Que las semillas tengan patente (algo inaudito en la historia de la humanidad) quiere decir que si alguna de ellas «llega volando a tu huerta y poliniza tus verduras, estas no serán tuyas y además te enfrentarás a los abogados de Monsanto» (Conill et al., 2012: 40). Sorprende que no haya generado alarma social el hecho de que el $70 \%$ del mercado mundial de semillas esté en manos de diez empresas y que el $95 \%$ de las cosechas de arroz mundiales se reduzca a cinco variedades, si bien es verdad que emergen iniciativas de todo tipo que intentan contrarrestar estas tendencias, como los bancos de semillas o los movimientos que defienden una alimentación de calidad. En efecto, el papel de la alimentación de calidad y de la democracia alimentaria en el proceso de apropiación compartida de los lugares por parte de agricultores y consumidores será clave en el futuro (Booth, 2015; Calle, Soler, Rivera, 2011; Ghiringhelli, 2014; Rinella, Okoronko, 2015), como lo será el paisaje creado y gestionado por estos agricultores y vinculado a una alimentación que es, sobre todo, un hecho cultural.

En definitiva, soy consciente de las grandes problemáticas que acechan no ya al mundo rural, sino a la alimentación de la humanidad, pero no puedo entrar en ellas en este artículo porque no son el tema central del mismo. Hecha 
la aclaración, veamos cuáles son estos indicios de nuevas ruralidades que van en la dirección del cambio de paradigma más arriba apuntado.

\section{Estamos asistiendo a la emergencia de un nuevo neorruralismo que va mucho} más allá del conocido fenómeno neorrural, tan importante en buena parte de Europa en las décadas de los años setenta y ochenta del pasado siglo. Las actuales tecnologías de la información y de la comunicación están influyendo en la aparición de estos nuevos tipos y modelos de asentamiento y cuestionan en su totalidad las tradicionales relaciones campo-ciudad (y el propio significado de ambos conceptos). Lo más interesante del caso es que, detrás de todo ello, subyace el deseo de experimentar una nueva forma de territorialidad, es decir, un cambio en las relaciones existentes entre las personas y su entorno biosocial; una nueva territorialidad que implica una revisión a fondo de categorías clave, como el trabajo o el capital (Nogué, 2012).

Es verdad que hoy se dan procesos migratorios hacia el campo que no tienen nada que ver con lo que se entiende habitualmente por fenómeno neorrural (Berger, Chevalier, Cortes, 2008), algunos — sobre todo en el caso español- como consecuencia de la crisis económica y del paro. Ya hay quien se dedica a estudiar esta concreta migración ciudad-campo, en la que no entraré a continuación, como tampoco entraré en otras tipologías específicas de repoblación del campo que se están dando en estos momentos. Me referiré solamente al fenómeno neorrural clásico por dos razones. En primer lugar, porque en buena parte de Europa el término continúa manteniendo el significado, la connotación que se le ha dado tradicionalmente, esto es el proceso de abandono de la ciudad y de asentamiento en el campo de un colectivo mayoritariamente joven en busca de un proyecto de vida alternativo, que puede ser tan diverso como diversas son las actividades que se pueden realizar. Y en segundo lugar, porque el fenómeno, como tal, no solo no ha desaparecido, sino que está más vivo que nunca, si bien - $\mathrm{y}$ es conveniente remarcarlo- con dos matices importantes: se ha diversificado y ensanchado enormemente tanto desde el punto de vista geográfico como sociológico, y — segundo matiz importanteel contexto cultural, económico y social de estos primeros años del siglo XXI es radicalmente distinto al de hace treinta o cuarenta años, empezando por las relaciones campo-ciudad e incluso por los propios conceptos de campo y ciudad.

Como es sabido, el fenómeno neorrural, tal y como lo hemos definido, aparece a finales de la década de los años sesenta y a principios de la de los setenta del siglo pasado en dos ámbitos geográficos muy concretos: Estados Unidos y lo que entonces se conocía como la Europa occidental. En Estados Unidos, por influencia de la llamada contracultura, que llevó a la creación de centenares de comunas rurales de inspiración hippy. En Europa, el fenómeno empezó a tomar forma después del Mayo del 68 francés (Mendras, 1979). Grupos de jóvenes cansados de la ciudad y contrarios al modelo de sociedad que el nuevo capitalismo iba configurando dejan la urbe en sucesivas etapas y se instalan en esos pueblos y casas abandonadas, a su vez, pocos años antes, por peque- 
ños campesinos y artesanos. Por primera vez en muchos años se produce una inversión de las migraciones, un retorno al campo, en modo alguno comparable —ni demográfica ni sociológicamente hablando- al éxodo rural que lo vació. Es fundamental tener en cuenta esta cuestión: el abandono del campo empieza con fuerza por aquellos años en países como Francia, Italia o España. Se inicia por las áreas más periféricas, aquellas en las que es más difícil, por no decir imposible, la reconversión de las explotaciones agrarias tradicionales en modernas explotaciones capitalistas que orienten su producción hacia el mercado y que exijan, para ser viables, grandes inversiones de capital. La alta y media montaña serán, por lo tanto, las primeras áreas en ser abandonadas: miles de pueblos del centro de España, del Pirineo y del Prepirineo, pero también del Macizo Central francés o de los contrafuertes alpinos franceses e italianos quedan abandonados en pocos años. No podemos incidir más en esta cuestión por falta de tiempo, pero es clave tenerla en cuenta si queremos entender la facilidad con la que los neorrurales encontraron alojamiento: sencillamente, podían escoger. La situación del mercado inmobiliario en esas áreas no es precisamente la misma hoy en día, como es de sobras conocido.

Después del Mayo del 68, unos cien mil jóvenes emprendieron en Francia el camino del campo buscando un ambiente más propicio que el que acababan de abandonar en la ciudad para poner en práctica sus planteamientos de vida alternativa. Todo el Mediodía francés y en especial la parte sur del Macizo Central, los Pirineos Orientales y las montañas de la Provenza y el sureste de los Prealpes se convirtieron en zonas de máxima concentración de grupos neorrurales, por su clima mediterráneo o submediterráneo, por la facilidad a la hora de encontrar vivienda y porque el precio de la tierra y de los alquileres, en tanto que áreas marginales y ligeramente alejadas de los grandes ejes de comunicación, era mucho más barato que en otras zonas, como ya he comentado. Constituyen esta primera ola jóvenes estudiantes y profesionales que provienen de una clase urbana media y que se organizan en forma de comunas, en general bastante radicalizadas y de carácter anarquista en su mayoría. Los conflictos que se originaron con la población autóctona, junto con su poca preparación técnica para convertir en mínimamente rentables las propias explotaciones agrícolas, explican que al cabo de pocos años, en 1973, el 95\% de aquellas comunidades hubiera desaparecido (Hervieu y Léger, 1979).

A partir de 1974 se origina en la mayoría de los países europeos una nueva ola de retorno al campo, de composición y significado muy diferentes a la anterior (Vuarin, 1982) y mucho más similar a la situación actual. En el caso francés, los nuevos neorrurales ya no se localizan exclusivamente en las áreas del Mediodía, sino que se distribuyen por todo el territorio. Se trata de grupos menos radicales y antisistema, influidos, en cualquier caso, por los planteamientos del movimiento ecologista. El principal objetivo ya no será la utopía comunitaria sino, sencillamente, el hecho de vivir en contacto directo con la naturaleza en pequeñas comunidades - normalmente, parejas - que se dedicarán a la artesanía y a la agricultura, entre otras actividades. Ya no se trata de ensayar grandes teorías utópicas, ni mucho menos de intentar convencer 
a nadie de su validez. Los miembros de esa segunda ola consiguieron no solo consolidar y hacer cuajar el fenómeno neorrural, sino también aumentar progresivamente el número de grupos y de personas que pueden englobarse bajo esta denominación. El movimiento neorrural aparece en España con un ligero retraso en relación con otros países europeos, aunque se observan claramente las dos primeras etapas u olas que comentábamos hace un momento para el caso francés y europeo en general.

He aquí, por tanto, un movimiento migratorio singular, que afecta de nuevo al mundo rural, cargado de un gran contenido ideológico y que se produce después de una decisión y una elección voluntarias de sus protagonistas. $\mathrm{Al}$ contrario del éxodo rural, forzado y provocado por los mismos mecanismos generados por la lógica capitalista, este movimiento se sitúa y actúa en parte fuera de la lógica del sistema, por lo que los conceptos de trabajo, tierra y capital no pueden aplicarse mecánicamente a este fenómeno, ya que se apartan de su significado normal en una sociedad rural habitual. El neorruralismo es algo más que un mero retorno al campo. Expresa, de hecho, un cambio de territorialidad; es decir, un cambio en las relaciones existentes entre los individuos y su entorno biosocial (Mercier y Simoni, 1983) o, si se prefiere, unas nuevas prácticas socioespaciales en el ámbito rural (Halfacree, 2006). No se responde solo a un modelo de sociedad en abstracto. Se responde también a su concepción dominante de la naturaleza, de los recursos naturales, del paisaje y, en definitiva, del espacio geográfico. En términos experienciales, siguiendo a Yi-Fu Tuan, se persigue pasar del «espacio» al «lugar» (Tuan, 1977).

Este es el neorruralismo que nos llega hasta hoy, consolidado ya plenamente en la década de los años ochenta, como hemos visto. Ha cambiado - y mucho- el contexto social, económico y cultural. La generalización del uso de internet y de las nuevas tecnologías de la información y de la comunicación facilitan la conexión en red y, lo que es más importante, el trabajo a distancia. Por otra parte, hemos asistido en los últimos treinta años a una especie de encogimiento del territorio: las nuevas vías de comunicación y las modernas telecomunicaciones permiten llegar a cualquier punto del territorio en muy poco tiempo, por lo que uno se puede plantear instalarse en un entorno rural disfrutando prácticamente de las mismas comodidades que en la ciudad o, como mínimo, siguiendo conectado a la ciudad y a todo lo que esta ofrece. Sin duda, el contexto y las reglas del juego han cambiado mucho, pero la esencia del neorruralismo de los ochenta (el de la segunda etapa) se mantiene, aunque ha incorporado nuevos ingredientes y nuevos lenguajes: se aspira a vivir en un entorno agradable, con un paisaje no degradado y singular y disfrutando al máximo de todo lo que sea natural, que a menudo es sinónimo de autóctono: los productos de la tierra, la filosofía del $\mathrm{km} 0$, la agricultura ecológica, la recreación de la artesanía local, etc. El fenómeno se ha volcado hacia cuestiones ambientales y de identidad territorial, y hacia la calidad de vida en general en un entorno sano y agradable. Se reforzará la vinculación entre productos autóctonos, paisaje e identidad territorial, lo que derivará, en muchos casos, en una profunda implicación en los conflictos territoriales propios del lugar escogido para vivir. 
2. Proliferan circuitos alternativos de producción y de consumo, basados en cooperativas de productos de proximidad e incluso en cooperativas de intercambio de servicios sin dinero de por medio. Léase cooperativismo, redes de trueque, moneda social, bancos de tiempo y otras prácticas que no priorizan el valor de cambio en las transacciones comerciales, sino el valor de uso. El protagonismo que están adquiriendo estas redes, desconocidas en buena medida por la propia Administración, es extraordinario. Muchas están vinculadas al fenómeno neorrural antes mencionado, pero otras muchas no, o no solamente. De hecho, muchos de estos circuitos son urbanos. Se extiende el "prosumo» y la figura del "prosumidor», así como las economías alternativas. Es aconsejable en este sentido la obra Otra vida es posible (Conill et al., 2012), en la que, tras unos años de intenso trabajo de campo, se detallan, solamente para el área metropolitana de Barcelona, decenas de prácticas de producción y de consumo alternativas, algunas de ellas surgidas a raíz de la crisis, pero muchas otras ya presentes desde hacía años, aunque quizá no con la visibilidad que han adquirido recientemente. Conclusión del libro: es extraordinario el número y el dinamismo de los colectivos que exploran modelos sostenibles de vida. "Como la crisis es estructural y falta dinero y sobra tiempo, los modelos de vida alternativa tienen un terreno abonado para crecer», afirman los autores con razón (p. 290). Modelos que ya se están implantando y que no provocan cambios estructurales visibles, pero sí miles y miles de microcambios, en su mayor parte desconocidos por la Administración. Microcambios en el campo y en la ciudad. Y entre el campo y la ciudad; un campo que a veces "ya» está en la ciudad, a través de los huertos urbanos (Baudelet, Basset y Le Roy, 2008) o de los descampados periféricos que han vuelto a cultivarse. El discurso de los «urbanos» que se mueven en estos circuitos alternativos es claramente convergente con el de los neorrurales y, de hecho, ambos rechazan la oposición ciudad-campo, rural-urbano.

3. Reinvención de antiguas profesiones como estrategia de recuperación del carácter del lugar. Es, de nuevo, la sociedad civil la que se ha avanzado en este terreno y, con imaginación, está «reinventando» antiguas profesiones casi extinguidas como medio para la recuperación del carácter del lugar. Las escuelas de pastores, con un éxito extraordinario, son un interesante ejemplo de ello.

4. La recuperación de la esencia del lugar como estrategia de revitalización económica y cambio cultural. Un ejemplo: El Priorat, una comarca de montaña media-baja mediterránea que hace tan solo veinticinco años había casi desaparecido del mapa, es decir estaba a un paso de la despoblación total. Hoy ha renacido de las cenizas gracias a la recuperación del sentido de lugar y a un inteligente proceso de reemocionalización ciudadana ante el propio paisaje, que lo ha hecho más atractivo a inversiones endógenas y exógenas. Creo que hay muchas comarcas, muchas zonas del Estado que están a un paso de vivir un proceso similar. A menudo, lo que tan solo les falta es un nuevo discurso territorial liderado por unos agentes sociales, económicos y culturales más activos, dinámicos y abiertos que miren «lo rural» con otros ojos y que sean capaces de captar los valores y potencialidades del paisaje autóctono, a menudo 
minusvalorado por los propios lugareños, sobre todo si ha sido una tierra de emigración. Hay que ensanchar el concepto de desarrollo local, y más aún si se trata de zonas rurales. Hay que ensancharlo para introducir otras muchas variables, como la cultural, el siguiente ejemplo que quería sacar a colación.

5. Revitalización de áreas marginales y despobladas a través de proyectos culturales de calidad. Me refiero a experiencias de recuperación de áreas rurales despobladas y abandonadas basadas en un proyecto cultural en mayúsculas, y no en un proyecto estándar de tipo económico, ya sea turístico o agrícola. Un proyecto cultural que podría haberse desarrollado perfectamente en la ciudad, pero que se decide hacer en el campo, sacando partido de un paisaje determinado, de un entorno especial. Existen varios ejemplos de este tipo repartidos por toda Europa, entre ellos uno que me parece de especial interés: el Centro de Arte y Naturaleza (CAN: www.farreracan.cat) de Farrera, en medio de los Pirineos catalanes. Artistas, poetas, escritores, es decir gente del mundo de la cultura en general procedente de los cinco continentes, realizan estancias en este centro durante las cuales generan su obra inspirándose en la identidad del lugar. Resultado: se ha revitalizado de nuevo una comunidad rural local que se estaba extinguiendo.

6. Están apareciendo nuevas formas de gestión del territorio de carácter horizontal, comunitario y no recogidas inicialmente por la legislación vigente. Las Redes de Custodia del Territorio gestionan, desde la sociedad civil, un elevadísimo número de propiedades que se estaban abandonando a marchas forzadas y me parecen un ejemplo interesante de nuevas formas de gestión que irán apareciendo con el tiempo. He ahí una muestra de que la gestión sostenible y respetuosa del territorio ya no está solamente en manos de la Administración. Es cada vez más horizontal y menos vertical.

7. El reencuentro con el lugar está siendo posible gracias a nuevas formas de gobernanza local. Hay muchas agrupaciones de pequeños municipios rurales que están impulsando proyectos interesantísimos de recuperación del lugar, de carácter multifuncional y muchas veces sin ningún tipo de ayuda oficial, ni del Estado ni de la UE. Se trata de experiencias de revalorización de territorios a partir del fortalecimiento de las relaciones lugar-comunidad, siempre expresadas a través de un paisaje determinado (Benoit, Deffontaines y Lardon, 2006; Brunori, Marangon y Reho, 2007). Es el caso, por ejemplo, de la asociación de municipios Borghi Attivi (www.borghiattivi.it), de la región italiana de Los Abruzos, una región montañosa del centro de Italia que aún padece las consecuencias del terrible terremoto del 6 de abril de 2009, que dejó la capital, L’Aquila, devastada, y decenas de pueblos medio derruidos. El proceso de reconstrucción de estos pueblos va mucho más allá de su reconstrucción física. Bajo el lema Participar y reconstruir, están poniendo en práctica un programa de actuaciones denominado «Laboratorio de democracia deliberativa» que consiste, fundamentalmente, en recuperar y fortalecer el sentido del lugar y el sentido de comunidad, muy debilitado ya desde hacía años por una emigración constante de los jóvenes más emprendedores hacia las grandes ciudades italianas. La reconstrucción física de los edificios destrozados por el 
terremoto no es más que una parte de un programa de actuaciones mucho más amplio, siempre apoyado en una auténtica participación ciudadana. De lo que se trata, en palabras de la joven alcaldesa de Fontecchio, Sabrina Ciancone, es de convertir esta catástrofe natural en una ocasión para repensar el territorio colectivamente, fortalecer de nuevo una identidad local que llevaba años diluyéndose y reencontrar en el paisaje aquellos elementos identitarios y referenciales que siempre habían dado cohesión a la comunidad, pero que, a raíz de la emigración hacia la ciudad, los propios autóctonos habían infravalorado. Se trata de recuperar el sentido del lugar y de renacer de las cenizas no solo físicamente sino también mentalmente.

8. Y, finalmente, quería referirme de manera breve al renovado papel de los centros de estudios locales y comarcales. Al menos en Cataluña, el caso que conozco más de cerca, no hay capital comarcal ni pueblo de tamaño medio que no disponga de su centro de estudios local. Pues bien, estos centros están pasando de ser marginales asociaciones constituidas por unos pocos eruditos locales de avanzada edad interesados por la historia del lugar a espacios de encuentro y de sociabilidad entre nuevos y viejos pobladores, así como puntos de difusión de la cultura local y de generación de nuevas perspectivas sobre el lugar. Es extraordinario y sorprendente el renovado dinamismo que han adquirido en los últimos diez años, no todos ellos, claro está, pero sí una gran mayoría. Languidecían, se extinguían y, de pronto, han renacido. Es como si, de la noche a la mañana, se hubiera despertado el interés por la historia y la geografía del lugar y del entorno rural que los acompaña. Hay quien aduce que, de nuevo, la explicación se halla en los efectos inducidos por la crisis. No lo sé, no lo descarto, pero sí sé que este fenómeno tiene mucho que ver con el título de este artículo, es decir, con el reencuentro con el lugar, con las nuevas ruralidades y con el cambio de paradigma aquí aludido.

\section{Conclusiones}

¿Qué tienen en común estas y otras muchas experiencias similares que no se han comentado en este artículo? Muchas cosas. Voy a señalar dos de ellas. En primer lugar, sociológicamente y mentalmente hablando, una difuminación prácticamente total de las tradicionales barreras conceptuales y funcionales campo-ciudad. Ya no nos explican gran cosa en este terreno. No es solamente que las tecnologías de la información y las nuevas vías de comunicación hayan acercado como nunca antes estos dos mundos, sino que los propios colectivos, las propias personas - y muy especialmente los nuevos pobladores - pertenecen, simultáneamente, a ambos mundos. Mentalmente, funcionalmente e incluso en términos de sociabilidad. Estamos, sin duda, ante un nuevo panorama.

Otro rasgo en común que detecto en todas estas y otras tantas experiencias similares tiene que ver con la idea de bien común aplicada al espacio geográfico y también al paisaje. Subyace en estas experiencias, ya sea de manera explícita o implícita, una idea de bien común entendido como una tercera categoría, como una tercera vía entre la propiedad privada y la propiedad estatal (o pública, 
si se prefiere). No quiero extenderme en esta cuestión aquí y ahora, porque no es el momento, pero sí dejar constancia de que algo se mueve también en ese terreno. La modernidad instauró un sistema basado en dos polos de poder y de legitimidad opuestos: el del estado soberano y el de la propiedad privada, presentados ambos como las dos caras de la misma moneda. La lógica del positivismo científico cartesiano acabaría bendiciendo académicamente esta dualidad. El peso específico de uno u otro polo variará en función del contexto histórico y geográfico, pero los dos se convertirán en los pilares de la retórica moderna al impregnar el imaginario colectivo y anular todas las formas premodernas de gestión de lo común, que, después de unos cuantos siglos, se afanan por reaparecer, obviamente en un formato diferente. La restitución de la esencia del concepto de bien común choca de lleno con esta retórica y con todo el corpus jurídico e institucional que se deriva de la misma, lo que explica sus dificultades para abrirse camino. Pero lo hará, entre otras razones, porque la actual crisis ha puesto de manifiesto que no es verdad que no existan otras alternativas, otras formas de organización y de control social de aquello que es común. Está emergiendo otra narrativa del espacio público y del paisaje basada en la idea de bien común, y esta es una muy buena noticia. Y cito en este punto un pequeño párrafo del libro de Ugo Mattei, Beni comune. Un manifesto (2011: 52), que en Italia ha generado un gran debate público:

Un bien común, a diferencia tanto de la propiedad privada como de la estatal, no se puede concebir solamente como un objeto, como una simple porción tangible del mundo externo. No se corresponde con la lógica mecanicista y reduccionista típica de la Ilustración, aquella que separa nítidamente el sujeto del objeto. Un bien común existe sobre todo en términos cualitativos y no puede ser reducido a la idea moderna de mercancía. No «tenemos» un bien común (como el agua), sino que somos partícipes de este bien común; en cierto modo, «somos» parte del bien común. [...] Por ejemplo, una plaza no es un bien común en tanto que espacio físico, sino en tanto que un lugar de sociabilidad y de intercambio existencial. [...] En el terreno de los bienes públicos, el sujeto es parte del objeto (y al revés). [...] Nosotros también somos lo común.

Dejo aquí el tema y remarco de nuevo que la mayor parte de estrategias de recuperación y reencuentro con el lugar que hemos visto llevan implícita esta concepción.

En definitiva y ya para terminar: estoy totalmente convencido de que estamos asistiendo a un reencuentro con el lugar a través de nuevas e imaginativas fórmulas como resultado de un cambio de paradigma liderado por una sociedad civil que entiende la acción política de otra manera. Una sociedad civil que no tiene ningún problema en reconocer la importancia que tiene vincular las emociones a los lugares, a los paisajes y, en general, a la gestión del espacio público. Detecto en el mundo rural nuevos proyectos y actitudes, nuevos valores, nuevas formas de organización social que, en algunos casos, emergen casi de la nada y, en otros, se han reforzado precisamente gracias a la 
hecatombe económica, social y cultural provocada por la tan manida crisis. Es palpable en la sociedad el deseo de experimentar nuevas formas de relacionarnos con el entorno. Se «redescubre» el lugar en el que se habita y, si uno está atento, se perciben con claridad las ganas que la gente tiene de interaccionar con sus lugares de manera algo más intensa, profunda y a la vez pausada de lo que hicimos hasta hace dos días. Mi impresión personal —obviamente, no demostrable hasta dentro de unos cuantos años- es que los fenómenos aquí descritos, muchos de ellos incipientes, irán a más en el futuro, por muchas y diversas razones, pero también, y sobre todo, porque conectan perfectamente con una profunda corriente social y cultural que reclama un nuevo modo de relacionarnos con el entorno que nos rodea, que reclama un nuevo modo de curare la terra, en definitiva.

\section{Referencias bibliográficas}

Aubert, Francis; Piveteau, Vincent y Schmitt, Bertrand (eds.) (2009). Politiques agricoles et territoires. Versalles: Quae.

BAudelet, Laurence; Basset, Frédérique y Le Roy, Alice (2008). Jardins partagés: utopie, écologie, conseils pratiques. Mens: Terre Vivante.

Benoît, M.; Deffontaines, J.-P. y Lardon, S. (2006). Acteurs et territoires locaux: vers une géoagronomie de l'aménagement. París: INRA.

Berger, Alain; Chevalier, Pascal y Cortes, Geneviève (eds.) (2008). Paradis verts : désirs de campagne et passions résidentielles. París: Payot.

Воотн, Sue (2015). Food democracy. From consumer to food citizen. Singapur: Springer Singapore.

BRUNO, Jean (2014). «A new paradigm of rural innovation: Learning from and with rural people and communities». Innovation and Modernising the Rural Economy. París: OECD, 113-126.

Brunori, Gianluca; Marangon, Francesco y Reho, Matelda (2007). La gestione del paesaggio rurale tra governo e governance territoriale: continuita e innovazione. Milán: Franco Angeli.

Calle, Ángel; Soler, Marta y Rivera, Marta G. (2011). «La democracia alimentaria: soberanía alimentaria y agroecología emergente». En: Collado, Ángel (coord.). Democracia radical: entre vinculos y utopias. Barcelona: Icaria, 213-238.

Carlson, Allen (2009). Nature and Landscape. An Introduction to Environmental Aesthetics. Columbia: Columbia University Press.

Clementi, Luciana Vanesa (2012). «Del nostálgico recuerdo al creciente entusiasmo por lo rural. Indicios de la revalorización y el retorno a los espacios rurales». GeoGraphos: Revista Digital para Estudiantes de Geografia y Ciencias Sociales, 3: 30, $1-25$.

Conill, Joana; Cárdennas, Amalia; Castells, Manuel; Hlebik, Sviatlana y Servon, Lisa (2012). Otra vida es posible. Prácticas económicas alternativas durante la crisis. Barcelona: UOC.

Ghiringhelli, Barbara (2014). La sfida del cibo. Alimentazione, cultura e territorio. Roma: Carocci.

Halfacree, Keith (2006). «From Dropping Out to Leading On? British Countercultural Back-to-the-Land in a Changing Rurality». Progress in Human Geography, 30, 309-336. 
Hervieu, Bertrand y LÉGer, Daniel (1979). Le retour à la nature, «au fond de la forêt... l'État». París: Le Seuil.

Mattei, Ugo (2011). Beni comune: un manifesto. Bari: Laterza.

Mendras, Henri (1979). Voyage au Pays de l'Utopie Rustique. Le Paradou: Actes-Sud.

Mercier, Claude y Simona, Giovanni (1983). «Le néo-ruralisme. Nouvelles approches pour un phénomène nouveau». Revue de Géographie Alpine, LxxI-3, 253-265.

Nogué, Joan (2010). Paisatge, territori i societat civil. València: Tres i Quatre.

- (2012). "Neo-ruralism in the European Context. Origins and Evolution». En: Resina, Joan-Ramon y Viestenz, William R. (eds.). The New Ruralism. An Epistemology of Transformation Space. Madrid y Frankfurt: Vervuert - Iberoamericana, 27-40.

Palang, Hannes (ed.) (2004). European Rural Landscapes: Persistence and Change in a Globalising Environment. Dordrecht: Kluwer Academic Publishers.

Pascale, Alfonso (2014). "Una nuova ruralità. Ritorno alla terra o correttivo di civiltà». Oliofficina Magazine. <http://www.olioofficina.it/saperi/focus/una-nuovaruralita.htm> [consulta: 11 de marzo de 2016].

Perrier-Cornet, Philippe (ed.) (2002). Repenser les campagnes. París: L’Aube.

Rauch, T. (2014). "New ruralities in the context of global economic and environmental change - are small-scale farmers bound to disappear?». Geographica Helvetica, 69, 227-237.

RENARD, Jean (2002). Les mutations des campagnes : paysages et structures agraires dans le monde. París: Armand Colin.

Rinella, Angelo y Oковоnко, Helen (2015). «Food Sovereignty Processes of Democratisation of the Food Systems and the Right to Food». Revista General de Derecho Público Comparado, 17.

Rubino, Adalgisa (2010). La nuova ruralità. Florencia: Università di Firenze. Laboratorio di Progettazione Ecologica degli Insediamenti.

Tuan, Yi-Fu (1977). Space and Place: The Perspective of Experience. Londres: Arnold.

VuARIN, Robert (1982). Le recours à la terre. Essai de compréhension de la structure et explication de la genèse du mouvement contemporain d'installation à la terre de non-agriculteurs. Marsella: Université de Provence. Département de SociologieEthnologie. Tesis doctoral.

Wolfer, Bernard A. (ed.) (2010). Agricultures et paysanneries du monde : mondes en mouvement, politiques en transition. Versalles: Quae. 